\title{
Possible Health Risk of Electromagnetic Fields
}

\author{
Teslime Esra Sarı ${ }^{1}$, Feyza Kelleci' ${ }^{1}$, Mohammad Charehsaz ${ }^{1}$, Ahmet Aydın ${ }^{1 *}$ \\ ${ }^{1}$ Yeditepe University, Faculty of Pharmacy, Department of Pharmaceutical Toxicology, 34100 Istanbul, TURKEY
}

\begin{abstract}
Electromagnetic field (EMF) is a kind of radiation and is emitted to environment from some medical diagnostic equipment, radio and television, communication devices such as cell phones, and other electrical appliances. It can have some risks to biological systems. There are some published documents on the possible human health risks of it including epidemiologic, in vivo, and in vitro studies. This review article focuses on the advers health effects of electromagnetic fields on reproductive and developmental system, psychological system, nervous system, genotoxic effects, carcinogenesis, ear and vestibular system, ocular system, melatonin production and circadian rhythms. Although there are some studies which indicated some possible effects on these physiological systems, the data is limited to reach exact conclusion. Further studies are needed to prove safety and biological effects of EMF.
\end{abstract}

Key words: Electromagnetic field, electromagnetic radiation, health risks

\section{INTRODUCTION}

\section{Electromagnetic fields (EMFs)}

Electromagnetic fields (EMFs) are emitted to environment from radio and television, communication devices such as cell phones, and other electrical appliances at homes and workplaces. EMF composed of waves of electric and magnetic energy moving together through space. It is a type of radiation which is emitted by all cell phones. Different types of electromagnetic energy are categorized by their wavelengths and frequencies and comprise the electromagnetic spectrum. Different technologies use different radiation frequency. During recent years, people exposed to EMF radiation with widespread use of cell phones or their

${ }^{*}$ Corresponding author: Ahmet Aydın

E-mail address: ahmet.aydin@yeditepe.edu.tr; Tel: +90 2165782242 
base station. This station could affect people's health ${ }^{1,2}$. Electromagnetic radiation (EMR) is radiated from the electrically charged particles and also called electromagnetic wave (EMW). They travel through air and in other substances ${ }^{3}$.

\section{Classification of EMWs}

EMWs can be classified as ionizing and non-ionizing radiation according to their frequency and energy. Non-ionizing radiation refers to any type of EMR that does not carry enough energy to remove an electron from an atom or a molecule. Sources of non-ionizing radiation include microwaves, radio waves, cordless phones, wireless networks (Wi-Fi), power lines and magnetic resonance imaging (MRIs). Ionizing radiation has high-frequency waves with enough energy to release electrons from molecules. It can damage the structure of cells in the body (including DNA). It has well-documented effects on human health. Ionizing radiation is emitted by radon, uranium, and other naturally occurring radioactive elements and is used for X-rays, nuclear medicine, and CT ("cat") scans ${ }^{3}$.

\section{Specific Absorption Rate (SAR)}

When an organism is exposed to EMFs, it absorbs energy. The amount of absorbed energy depends on many factors such as the frequency of the radiation, the power density, the electrical properties of the exposed tissues and the orientation and possible attenuation of the fields. Exposure to radiofrequency (RF) energy is determined by the SAR, a measure of the rate at which energy is absorbed by the body when exposed to RF. It is defined as the power absorbed per mass of tissue, measured in watts per kilogram $(\mathrm{W} / \mathrm{kg})^{4}$.

The SAR is commonly used to measure the power absorbed during MRI scans and from cell phones. The allowable SAR limit for the head is $2 \mathrm{~W} / \mathrm{kg}^{4}$.

\section{Health Risks of EMFs}

Previous studies reported that low-level exposure to EMF radiation could cause a wide range of health effects, including behavioral changes, effects on the reproductive system effects, changes in hormone levels, headaches, and cardiovascular effects.

\section{Reproduction and Developmental Disorders}

Infertility is worldwide problem. It is affected by not only medical problem but also a psychological stress, including anxiety, depression and problems in maintaining the marital relationship. Chromosomal abnormalities, micro deletions, cystic fibrosis, transmembrane conductance regulator mutations, genetic factors, environmental factor are major causes of infertility. Also life style like smoking and drinking may partake to infertility. Besides, radio and television 
which transmit radiofrequency electromagnetic waves (RF EMWs) with frequency ranging from $0.5 \mathrm{MHz}$ in the Amplitude Modulation (AM) radio band up to $30,000 \mathrm{MHz}$ in radar band can have some effects on the fertility. In addition, hair dryers, X-ray equipment, laboratory equipment (incubators, centrifuge), computers and cell phones are EMF producers ${ }^{5}$.

\section{Male infertility disorders}

It is important to investigate the effect of EMR on male fertility. A possible link between EMR emitted from cell phone and infertility were seen in several studies $^{5,6}$.

Exposure to radiofrequency electromagnetic radiation (RF EMR) and mild scrotal heating can induce DNA damage in mammalian spermatozoa, although the underlying mechanisms are unclear. The induction of DNA damage in spermatozoa has been associated with male infertility, early pregnancy loss and morbidity in the offspring, including childhood cancer.

EMF released by cell phone can have adverse effects on human fertilization potential. Various preliminary studies, though with limitations, have suggested a use-dependent decrease in seminal quality and testicular tissue damage in men using cell phones. However, the mode of this damage to male reproductive system by EMF is still unclear. At high intensities, EMF may cause reversible disruption of spermatogenesis because of heating properties of RF radiations lead to thermal effects. High-quality research is still needed in this field ${ }^{6}$.

Wang et. al. reported that Leydig cells injury may affect spermatogenesis on mice ${ }^{7}$. These cells are among the most susceptible cells in to EMF. On the other hand, 890-915 MHz EMF exposure to rats for 20 min per day for 1 month resulted as no effects on the testis of rats $^{8}$.

The first human study was designed to evaluate the infertility problem on men, the duration of cell phone use was correlated negatively with the proportion of rapidly progressive motile spermatozoa. The prolonged use of cell phone might have negative effects on the sperm motility ${ }^{9}$.

Another experimental study was done to determine the biological and morphological effects of $900 \mathrm{MHz}$ EMF on male rat testes for 4 weeks. The results revealed a decrease in seminiferous tubular diameter and epithelium thickness without effect on spermatogenesis after applying of $900 \mathrm{MHz}$. There was also a significant decrease in serum total testosterone level and not a statistically significant decrease in luteinizing hormone and follicle stimulating hormone levels ${ }^{10}$. 
Significant damage to mitochondrial and nuclear genome was observed in a study conducted on epididymal spermatozoa of mice with $900 \mathrm{MHz}$ EMF for 7 days and $12 \mathrm{~h}$ a day ${ }^{11}$.

An another study was designed on semen samples of 27 healthy men exposed to $900 \mathrm{MHz}$ cell phone at distance of $10 \mathrm{~cm}$ for $5 \mathrm{~min}$. Significant decrease in rapid progressive motility, increase in slow progressive motility and increase in the percentage of immotile spermatozoa were observed in that study ${ }^{12}$.

The effect of cellular phone use on the fertility of males subjected to marital infertility therapy was assessed by Wdoviak et.al. A decrease in the percentage of live sperm cells in a vital, progressive motility in semen is correlated with the frequency of use of cell phones. An increase in the percentage of sperm cells with abnormal morphology is associated with the duration of exposure to the waves emitted by GSM equipment ${ }^{13}$.

The use of cell phones adversely affected the quality of semen by decreasing the sperm counts, motility, viability and morphology in related to daily active cell phone use and talking time of $\operatorname{man}^{14}$.

To see microscopic changes in the seminiferous tubules, male rats were exposed to EMF (1835 to $1850 \mathrm{MHz}$ ) from cell phones. Each cage was provided with 8 cell phone sets in active silent mode. These cell phones were kept in a small metal cage with a wooden bottom in order to address concerns that the effects of exposure to the phones could be due to heat emitted by phones rather than to RF EMW alone. These small cages which were then placed in the plastic cages of rats. It was resulted histological and morphological effects of testes. This investigation showed that number of seminiferous tubules were decreased significantly in exposed subgroups day by day after 110 day. At the same time diameter of seminiferous tubules were decreased ${ }^{5}$.

In contrast to possible adverse effect of EMF, the main bio functional sperm parameters in healthy men exposed to the different use of the cell phone were investigated. The results showed that none of the conventional sperm parameters examined were significantly altered. The trousers users showed a higher percentage of sperm DNA fragmentation compared to other groups ${ }^{15}$.

\section{Female sexual function and fertility disorders}

There is limited data on the association between EMF exposure during pregnancy and reproductive outcomes. Some studies have reported increased risk of spontaneous abortions and congenital malformations ${ }^{16}$.

The effect of EMF on early development of chick embryos was investigated. EMF 
exposed groups were influenced the mortality ratio when the exposure duration and the power level was increased. High frequency electromagnetic field can be responsible for the alterations in growth and development in ovo amniotic vertebrates ${ }^{17}$.

EMF emitted by Wi-Fi (2.45 GHz) and cell phone (900 and $1800 \mathrm{MHz}$ ) were studied to evaluate the effects on oxidative stress and trace element levels in the kidney and testes of growing rats from pregnancy to 6 weeks of age. Lipid peroxidation and oxidizable iron content increased and antioxidant trace elements (copper and zinc), and glutathione levels decreased during kidney and testis development ${ }^{18}$.

\section{Psychological Disorders}

Babadi-Akashe et. al. studied the behavior of cell phone addicts and mental health of university students. They found that the rates of students' addiction to cell phones reduced in related to increased and improved mental health ${ }^{19}$.

\section{Nervous System Disorders}

Narayanan et. al studied the brain effects of the EMF emitted from the cell phones in rat and the quite substantial hazard on passive avoidance behavior and hippocampal morphology in rats was detected ${ }^{20}$. EMF from cellular phones did not lead to anxiety or not cause impairment of the working memory, but it may cause stressful behavior pattern in rats ${ }^{21}$. Decreased immobility and increased locomotor activity were seen in rats after exposure to $\mathrm{EMF}^{22}$. The spatial learning and memory function of mice were affected after exposure to EMF33.

Fragopoulou et. al. found out no significant differences in the spatial memory test, and morphological assessment of the brain of rats after EMF exposure. However, in some exposed animals, there were decreased locomotor activity, increased grooming and tendency of increased basal corticosterone levels. These findings suggested that EMF exposure may lead to abnormal brain functioning ${ }^{24}$.

The possible link between cellular telephone use and risks for various diseases of the CNS such as Alzheimer's disease, migraine, or vertigo was investigated. It was found a weak, but a statistically significant association between cell phone use and migraine and vertigo ${ }^{25}$.

\section{The blood brain barrier (BBB) damage}

The human brain is surrounded by a layer of specialized cells which act as a barrier between brain and the contents of bloodstream. This barrier prevents toxins from reaching brain and maintains a healthy environment for brain tissue. Nittby et. al. studied the effect of EMF on BBB permeability in rats. It was found that the EMF exposure reduced memory functions ${ }^{26}$. 


\section{Genotoxic Effects/Cell Damage}

The potential of RF EMF to cause changes in a cell's genetic material (DNA) and/ or to damage the genome is an important research area. Genotoxic substances can potentially cause mutations or cellular damage that can contribute to the development of malign tumors. It was reported a positive correlation among EMF exposure from mobile phones and DNA damage, chromosomal aberration, increased sister chromatide exchange frequencies in humans ${ }^{27,28,29}$.

Ferreira et. al. investigated the effects of ultra high frequency-electromagnetic field (UHF-EMF) on micronucleus formation in erythrocytes and imbalances in free radical metabolism in liver and blood of rat offspring whose mothers were irradiated during the pregnancy. The study was resulted that UHF-EMF was indeed able to generate cell chromosome damage transplacentally. However the effects of free radical metabolism on this damage was not clear ${ }^{30}$.

Gandhi and Singh reported an increased micronucleated buccal cells and cytological abnormalities in cultured lymphocytes of individuals exposed to EMF from mobile phones ${ }^{31,32}$.

EMF induced DNA single-strand and double-strand breaks in human diploid fibroblasts and in rat granulosa cells in culture were also reported ${ }^{33}$.

\section{Carcinogenic Effects}

Several studies showed that long-term exposures to EMF caused an increase in the risk of some types of tumors, but experimental studies were not available to explain the exact association. Overall, the epidemiological studies on the possible relationship between EMF exposure from mobile communicating devices and cancer have been conducted. Most of these studies have focused on brain tumors. Some have found a risk of cancer with long-term exposure while others have not.

Due to head exposure to EMF released from mobile communicating devices, studies mainly focused on the relationship between EMF exposure and brain tumors ${ }^{34}$.

International Agency for Research on Cancer (IARCH) coordinated a study in 1998 and 1999. They concluded that the relationship between cell phone use and brain tumor risk would be feasible and informative ${ }^{35}$.

Holding a cell phone to the ear can result in high SAR values in the brain depending on the EMF released from mobile communicating devices, their holding places in the body and the quality of the link between the base station and device. Cancer risk is limited for two types of brain tumor: glioma and neuroma. Although there was some statistically significant evidence about the association 
between EMF from cell phone use and brain tumor risks, most studies showed no association ${ }^{36}$.

Long term epidemiological studies for an association between long-term cell phone use and the risk of brain tumor showed a link between prolonged cell phone use and ipsilateral brain tumor, but the observed effect was not extended to meningiomas ${ }^{37,38}$.

Hardel et. al. evaluated the risk of brain tumors with long-term use of cell phone. The result showed that long-term use (10 years or more) of cell phones was associated with increased risk of brain tumors (ipsilateral glioma and acoustic neuroma). However, no association was found for contralateral tumours ${ }^{39}$.

Lagario et. al. assessed the intracranial tumors and cell phone use and they reported the occurrence of intracranial tumors. In addition, they stated the combined relative risk in long-term cell phone users ( $\geq 10$ years) for meningioma ${ }^{40}$.

Relationship between glioma and use of cell phones and cordless phones was assessed by Hardel et.al. The risk of glioma with use of cell phones in the $>25$ year latency group and increased risk was observed with the use of cordless phones in the $>15-20$ year $^{41}$.

On the other hand there were some studies showing no association between brain tumors and cell phone use, but a possible association was estabilished between heavy cell phone use and brain tumors ${ }^{42}$. The study conducted to evaluate the risk of malignant melanoma in the head and neck regions was resulted no association on long term cell phone use of more than 10 years and total wireless use ${ }^{43}$.

Although there were some studies on the risk of brain tumor, there were limited data about the other cancer risks. Paulsen et. al. conducted a cohort study to evaluate skin cancer risk and mobile phone use. They reported no correleation ${ }^{44}$.

\section{Ear and Vestibular System Disorders}

Cell phones are usually held in close proximity to the ear. These exposures could have an adverse effect on hearing function either at the level of inner ear or on the central auditory pathways.

Hutter at.al. reported that high intensity and long duration of cell phone use might be associated with tinnitus ${ }^{45}$. After long-term and intensive cell phone use, inner ear damage and hearing loss may be seen ${ }^{46,47,48}$.

The effect of long term cell phone use on auditory brainstem evoked responses was studied and it was resulted in no effect on auditory pathways from cochlear nerve to auditory brainstem ${ }^{49}$. 


\section{Ocular Effects}

Eyes are unprotected by the skull and comprised of cells that are extremely sensitive to electromagnetic energy. The eyes can absorb electromagnetic energy very quickly.

The possible effects of long term use of cell phone on eyes of human was studied. Blurred vision, eye inflammation, lacrimation, redness in the eyes, visual disturbance and increased secretion of the eyes were reported ${ }^{50}$.

\section{Effects on Melatonin Production and Circadian Rhythms}

Melatonin is a hormone that controls circadian (sleep/wake) rhythms. It is secreted at night by the pineal gland and produces many biological effects. It also reduces risk of neurodegenerative diseases ${ }^{51}$.

Burch et. al. investigated the relationship between cellular telephone use and excretion of the melatonin. It was found that prolonged use of cellular telephones might lead to reduced melatonin production. Morover elevated EMR exposures may potentiate the effect ${ }^{52}$.

\section{Organ Damage}

Oktem et. al. examined 900-MHz cell phone-induced oxidative stress on renal tubular damage and the role of melatonin to protect kidney tissue against oxidative damage in rats. It was found the increase in malondialdehyde levels of renal tissue and $\mathrm{N}$-acetyl- $\beta$-D-glucosaminidase in urine and also the decrease in renal superoxide dismutase, catalase, and glutathione peroxidase activities. They demonstrated the role of oxidative stress induced by EMR, and the protective effect of melatonin against oxidative tissue injury in rat kidney53.

Erdem et. al. studied the effect of continuous exposure to $50 \mathrm{~Hz}$ EMF on the levels of trace elements in serum and different organs of Guinea pigs. They reported that $\mathrm{Cu}$ and $\mathrm{Mg}$ levels were affected in serum and tissue samples of these animals ${ }^{54}$.

\section{CONCLUSION}

As a conclusion, EMR emitted from different devices including communication technologies such as mobile phones, wireless equipments, television, electrical appliances can have different health risks to human. Users should be careful about the potential health risks and should control them to use of these devices. The time spent with the cellular devices should be reduced as low as possible. If possible speakerphone or a wired headset use could be recommended to reduce the exposure to EMR. The cell phone and other wireless devices should be kept 
several feet from the bed. Carrying a cell phone in pants or shirt pocket will emit EMR to nearby tissues. For this reason cell phones should carry away from body parts if it is possible.

\section{ACKNOWLEDGEMENT}

Special thanks to Electrical and Electronical Engineer Assoc. Prof. Dr. Serkan TOPALOĞLU.

\section{REFERENCES}

1. Repacholi, M.H. Health Risks From The Use of Mobile Phones. Toxicology Letters 2oo1, $120,323-331$.

2. Buckus, R., Strukcinskiene, B., Raistenskis, J. The Assessment of Electromagnetic Field Radiation Exposure For Mobile Phone Users. Vojnosanitetski Pregled 2014, 71, 1138-1143.

3. Zamanian, A., Hardiman, C. Electromagnetic Radiation and Human Health: A Review of Sources and Effects. High Frequency Electronics 2005, 16-26.

4. Possible effects of Electromagnetic Fields (EMF) on Human Health. European Commission Scientific Committee On Emerging And Newly Identified Health Risks (SCENIHR) 2007.

5. Qureshi, G.S., Jabeen, S., Parveen, S., Yasmin, T. Effects of Electromagnetic Radiations Produced by Cell Phones on The Number and Diameter of Seminiferous Tubules in Albino Rats. Medical Channel 2013, 119, 67-71.

6. Deepinder, F., Makker, K., Agarwal, A. Cell Phones and Male Infertility: Dissecting the Relationship. Reprod Biomed Online 2007, 15, 266-270.

7. Wang, S.M., Wang, D.W., Peng, R.Y., Gao, Y.B., Yang, Y., Hu, W.H., Chen, H.Y., Zhang, Y.R., Gao, Y. Effect of Electromagnetic Pulse Irradiation on Structure and Function of Leydig Cells in Mice. Zhonghua Nan Ke Xue 2003, 9, 327-330.

8. Dasdag, S.; Zulkuf Akdag, M.; Aksen, F.; Yilmaz, F.; Bashan, M.; Mutlu Dasdag, M.; Salih Celik, M. Whole Body Exposure of Rats to Microwaves Emitted From a Cell Phone Does not Affect The Testes. Bioelectromagnetics 2003, 24, 182-188.

9. Fejes, I.; Zavaczki, Z.; Szollosi, J.; Koloszár, S.; Daru, J.; Kovács, L.; Pál, A. Is There a Relationship Between Cell Phone Use and Semen Quality? Arch Androl 2005, 51, 385-393.

10. Ozguner, M.; Koyu, A.; Cesur, G.; Ural, M.; Ozguner, F.; Gokcimen, A.; Delibas, N. Biological and Morphological Effects on The Reproductive Organ of Rats After Exposure to Electromagnetic Field. Saudi Med $J$ 20o, 26, 405-410.

11. Aitken, R.J.; Bennetts, L.E.; Sawyer, D.; Wiklendt, A.M.; King, B.V. Impact of Radio Frequency Electromagnetic Radiation on DNA Integrity in The Male Germline. Int J Androl 2oo, 28, 171-179.

12. Erogul, O.; Oztas, E.; Yildirim, I.; Kir, T.; Aydur, E.; Komesli, G.; Irkilata, H.C.; Irmak, M.K.; Peker, A.F. Effects of Electromagnetic Radiation From a Cellular Phone on Human Sperm Motility: An In Vitro Study. Arch Med Res 2oo6, 37, 840-843.

13. Wdowiak. A.; Wdowiak, L.; Wdowiak, H. Evaluation of The Effect of Using Mobile Phones on Male Fertility. Ann Agric Environ Med 2007, 14, 169-172.

14. Agarwal, A.; Deepinder, F.; Sharma, R.K.; Ranga, G.; Li, J. Effect of Cell Phone Usage on Se- 
men Analysis in Men Attending Infertility Clinic: An Observational Study. Fertil Steril 2oo8, $89,124-8$.

15. Rago, R., Salacone, P.; Caponecchia, L.; Sebastianelli, A.; Marcucci, I.; Calogero, A.E., Condorelli, R., Vicari, E.; Morgia, G.; Favilla, V.; Cimino, S.; Arcoria, A.F.; La Vignera, S. The Semen Quality of The Mobile Phone Users. $J$ Endocrinol Invest 2003, 36, 970-974.

16. Mahmoudabadi, F.S.; Ziaei, S.; Firoozabadi, M.; Kazemnejad, A. Use of Mobile Phone During Pregnancy and The Risk of Spontaneous Abortion. IAEH 2015, 13, 34.

17. Jyoti, Kohli, R.K.; Bagai, U. Effect of Mobile Phone Frequency Radiation on Early Development of Chick Embryo. IJEST 2o14, 3, 1273-1280.

18. Ozorak, A.; Nazıroğlu, M.; Çelik, O.; Yüksel, M.; Özçelik, D.; Özkaya, M.O.; Çetin, H.; Kahya, M.C.; Kose, S.A. Wi-Fi (2.45 GHz)- and Mobile Phone (900 and $1800 \mathrm{MHz}$ )-Induced Risks on Oxidative Stress and Elements in Kidney and Testis of Rats During Pregnancy and the Development of Offspring. Biol Trace Elem Res 2013, 156, 221-229.

19. Babadi-Akashe, Z.; Zamani, B.E.; Abedini, Y.; Akbari, H.; Hedayati, N. The Relationship Between Mental Health and Addiction to Mobile Phones Among University Students of Shahrekord, Iran. Addict Health 2014, 6, 93-99.

20. Narayanan, S.N.; Kumar, R.S.; Kumar Potu, B.; Nayak, S.; Bhat, P.G.; Mailankot, M. Effect of Radiofrequency Electromagnetic Radiations (RF-EMR) on Passive Avoidance Behaviour and Hippocampal Morphology in Wistar Rats. Ups J Med Sci 2010, 115, 91-96.

21. Júnior, L.C.; Guimarães Eda, S.; Musso, C.M.; Stabler, C.T.; Garcia, R.M.; Mourão-Júnior, C.A.; Andreazzi, A.E. Behavior and Memory Evaluation of Wistar Rats Exposed to 1.8 GHz Radiofrequency Electromagnetic Radiation. Neurological Research 2014, 36, 800-803.

22. Nagar, H.; Kumar, D.; Tiwari, D.K.; Dwivedi, G.; Tripathi, R.K.; Jena, J. Loranthus longiflorus Protect Central Nervous System Against Oxidative Damages of Electromagnetic Radiation on Rat. IJGP 2013, 7, 328-331.

23. Fragopoulou, A.F.; Miltiadous, P.; Stamatakis, A.; Stylianopoulou, F.; Koussoulakos, S.L.; Margaritis, L.H. Whole Body Exposure With GSM 90oMHz Affects Spatial Memory in Mice. Pathophysiology 2010, 17, 179-87.

24. Daniels, W.M.; Pitout, I.L.; Afullo, T.J.; Mabandla, M.V. The Effect of Electromagnetic Radiation in The Mobile Phone Range on The Behaviour of The Rat. Metab Brain Dis 2oog, 24, 629-641.

25. Schüz, J.; Waldemar, G.; Olsen, J.H.; Johansen, C. Risks for Central Nervous System Diseases Among Mobile Phone Subscribers: A Danish Retrospective Cohort Study. PLoS One 2oog, 4, e4389.

26. Nittby, H.; Brun, A.; Strömblad, S.; Moghadam, M.K.; Sun, W.; Malmgren, L.; Eberhardt, J.; Persson, B.R.; Salford, L.G. Nonthermal GSM RF and ELF EMF Effects Upon Rat BBB Permeability. Environmentalist 2011, 31, 140-148.

27. Gandhi, G.; Gandhi, A. Genetic Damage in Mobile Phone Users: Some Preliminary Findings. Indian J Hum Genet 2005, 11, 99-104.

28. Gadhia, P.K.; Shah, T.; Mistry, A.; Pithawala, M.; Tamakuvala, D. A Preliminary Study to Assess Possible Chromosomal Damage Among Users of Digital Mobile Phones. Electromagn Biol Med 2003, 22, 149-159.

29. Sahin, D.; Ozgur, E.; Guler, G.; Tomruk, A.; Unlu, I.; Sepici-Dinçel, A.; Seyhan, N. The 2100 
MHz Radiofrequency Radiation of a 3G-mobile Phone and The DNA Oxidative Damage in Brain. J Chem Neuroanat 2016, 75(Pt B), 94-98.

30. Ferreira, A.R.; Knakievicz, T.; Pasquali, M.A.; Gelain, D.P.; Dal-Pizzol, F.; Fernández, C.E.; de Salles, A.A.; Ferreira, H.B.; Moreira, J.C. Ultra High Frequency-Electromagnetic Field Irradiation During Pregnancy Leads to An Increase in Erythrocytes Micronuclei Incidence in Rat Offspring. Life Sci 2006, 80, 43-50.

31. Gandhi, G.; Singh, P. Cytogenetic Damage in Mobile Phone Users: Preliminary Data. Int $J$ Hum Genet 2005, 5, 259-265.

32. Yadav, A.S.; Sharma, M.K. Increased Frequency of Micronucleated Exfoliated Cells Among Humans Exposed In Vivo to Mobile Telephone Radiations. Mutat Res 2008, 650, 175-80.

33. Diem, E.; Schwarz, C.; Adlkofer, F.; Jahn, O.; Rüdiger, H. Non-thermal DNA Breakage by Mobile-phone Radiation (180o MHz) in Human Fibroblasts and In Transformed GFSH-R17 Rat Granulosa Cells in vitro. Mutat Res 2005, 583, 178-83.

34. Cardis, E. Brain Tumour Risk in Relation to Mobile Telephone Use: Results of The Interphone International Case-control Study. Int J Epidemiol 2o10, 39, 675-694.

35. Verschaeve, L. Environmental Impact of Radiofrequency Fields From Mobile Phone Base Stations. Critical Reviews in Environmental Science and Technology 2014, 44, 1313-1369.

36. Szmigielski, S. Cancer Risks Related to Low-Level RF/MW Exposures, Including Cell Phones. Electromagn Biol Med 2013, 32, 273-280.

37. Khurana, V.G.; Teo, C.; Kundi, M.; Hardell, L.; Carlberg, M. Cell Phones and Brain Tumors: A Review Including The Long-term Epidemiologic Data. Surg. Neurol 2009, 72, 205-214.

38. Carlberg, M.; Hardell, L. Pooled Analysis of Swedish Case-control Studies During 19972003 and 2007-2009 on Meningioma Risk Associated With The Use of Mobile and Cordless Phones. Oncol Rep 2015, 33, 3093-3098.

39. Hardell, L.; Carlberg, M.; Söderqvist, F.; Hansson Mild, K. Meta-analysis of Long-Term Mobile Phone Use and The Association With Brain Tumours. Int J Oncol 2oo8, 32, 1097-1103.

40. Lagorio, S.; Röösli, M. Mobile Phone Use and Risk of Intracranial Tumors: A Consistency Analysis. Bioelectromagnetics 2014, 35, 79-90.

41. Hardell, L.; Carlberg, M. Mobile Phone and Cordless Phone Use and The Risk for Glioma - Analysis of Pooled Case-control Studies in Sweden, 1997-2003 and 2007-2009. Pathophysiology 2015, 22, 1-13.

42. Coureau, G.; Bouvier, G.; Lebailly, P.; Fabbro-Peray, P.; Gruber, A.; Leffondre, K.; Guillamo, J.S.; Loiseau, H.; Mathoulin-Pelissier, S.; Salamon, R.; Baldi, I. Mobile Phone Use and Brain Tumours in the CERENAT Case-control Study. Occup Environ Med 2014, 71, 514-522.

43. Hardell, L.; Carlberg, M.; Hansson Mild, K.; Eriksson, M. Case-control Study on The Use of Mobile and Cordless Phones and The Risk For Malignant Melanoma in The Head and Neck Region. Pathophysiology 2011, 18, 325-333.

44. Poulsen, A.H.; Friis, S.; Johansen, C.; Jensen, A.; Frei, P.; Kjær, S.K.; Dalton, S.O.; Schüz, J. Mobile Phone Use and The Risk of Skin Cancer: A Nationwide Cohort Study in Denmark. American Journal of Epidemiology 2013, 178, 190-197.

45. Hutter, H.P.; Moshammer, H.; Wallner, P.; Cartellieri, M.; Denk-Linnert, D.M.; Katzinger, M.; Ehrenberger, K.; Kundi, M. Tinnitus and Mobile Phone Use. Occup Environ Med 2o10, 67, 804-808. 
46. Panda, N.K.; Jain, R.; Bakshi, J.; Munjal, S. Audiologic Disturbances in Long-term Mobile Phone Users. J Otolaryngol Head Neck Surg 2010, 39, 5-11.

47. Patel, H.; Qureshi, R. Effects of Long Term Use of Mobile Phones on Hearing Status of Healthy Individuals Compared to Infrequent Mobile Phone Users in Age Group of 15-40 years. IJSR 2013, 2, 177-179.

48. Karthikeyan, P.; Christian, J.S.; Audhya, A. Hearing Evaluation in Mobile Phone Users at a Tertiary Care Hospital. Indian Journal of Otology 2014, 20, 24-28.

49. Gupta, N.; Goyal, D.; Sharma, R.; Arora, K.S. Effect of Prolonged Use of Mobile Phone on Brainstem Auditory Evoked Potentials. J Clin Diagn Res 2015, 9, CCo7-CCo9.

50. Balik, H.H.; Turgut-Balik, D.; Balikci, K.; Özcan, C. Some Ocular Symptoms and Sensations Experienced by Long Term Users of Mobile Phones. Pathol Biol (Paris) 2005, 53, 88-91.

51. Trotti, L.M.; Karroum, E.G. Melatonin for Sleep Disorders in Patients with Neurodegenerative Diseases. Curr Neurol Neurosci Rep 2016, 16, 63.

52. Burch, J.B.; Reif, J.S.; Noonan, C.W.; Ichinose, T.; Bachand, A.M.; Koleber, T.L.; Yost, M.G. Melatonin Metabolite Excretion Among Cellular Telephone Users. Int J Radiat Biol 2oo2, 78, 1029-36.

53. Oktem, F.; Ozguner, F.; Mollaoglu, H.; Koyu, A.; Uz, E. Oxidative Damage in The Kidney Induced by $900-\mathrm{MHz}-\mathrm{emitted} \mathrm{Mobile} \mathrm{Phone:} \mathrm{Protection} \mathrm{by} \mathrm{Melatonin.} \mathrm{Arch} \mathrm{Med} \mathrm{Res} \mathrm{2005,}$ $36,350-5$.

54. Erdem, O.; Akay, C.; Cevher, S.C.; Canseven, A.G.; Aydın, A.; Seyhan, N. Effects of Intermittent and Continuous Magnetic Fields on Trace Element Levels in Guinea Pigs. Biol Trace Elem Res, In press, DOI 10.1007/s12011-017-1053-8

(Received 16 June 2017; accepted o6 July 2017) 